\title{
Desenvolvimento e caracterização de filmes compósitos de quitosana e zeólitas com prata
}

\section{Development and characterization of chitosan/silver zeolites composite films}

\author{
Patricia Hissae Yassue-Cordeiro ${ }^{1}$, Cassio Henrique Zandonai ${ }^{1}$, Classius Ferreira da Silva ${ }^{2}$ e \\ Nádia Regina Carmargo Fernandes-Machado ${ }^{1 *}$ \\ ${ }^{1}$ Laboratório de Catálise, Departamento de Engenharia Química, Universidade Estadual de \\ Maringá - UEM, Maringá, PR, Brasil \\ ${ }^{2}$ Laboratório de Biotecnologia e Produtos Naturais, Departamento de Ciências Exatas e da Terra, \\ Universidade Federal de São Paulo - UNIFESP, Diadema, SP, Brasil \\ *nadia@deq.uem.br
}

\begin{abstract}
Resumo
Zeólitas foram submetidas à troca iônica ou impregnação com prata e posteriormente adicionadas em filmes de quitosana para a confecção de curativos para queimaduras. As zeólitas foram avaliadas por Ressonância magnética nuclear $(\mathrm{RMN})$, Fluorescência de raios X por reflexão total (TXRF), Microscopia eletrônica de varredura (MEV). Os filmes poliméricos foram analisados com relação às suas propriedades mecânicas, permeabilidade ao vapor d'água (PVA) e liberação de prata. Observou-se que o procedimento de troca iônica não alterou a morfologia das zeólitas de partida. Grumos de zeólita foram observados nas micrografias dos filmes e estes influenciaram nas propriedades mecânicas devido à desorganizaçao local no empacotamento das cadeiras poliméricas da quitosana. A metodologia de troca iônica ou impregnação influenciou diretamente na quantidade de prata presente superficialmente na zeólita e consequentemente alterou o perfil de liberação de prata em uma solução simulada de exudato de ferida. Os modelos cinéticos sugeriram que a liberação da prata não foi essencialmente regulada pela lei de difusão de Fick.
\end{abstract}

Palavras-chave: impregnação, troca-iônica, curativos para queimados, zeólita $Y$.

\begin{abstract}
Zeolites were subjected to ion exchange or impregnation with silver and added to chitosan films for producing burns dressings. Zeolites were characterized by nuclear magnetic resonance (NMR), total reflection X-ray fluorescence (TXRF), scanning electron microscopy (SEM). The polymer films were analyzed with respect to their mechanical properties, water vapor permeability (WVP), and release of silver. It was observed that the ion exchange did not modify the morphology of the starting zeolite. Clusters of zeolite were observed in the micrographs of the films and they influenced the mechanical properties due to local disruption in the packing of the polymer chains of chitosan. The methodology of ion exchange or impregnation directly influenced the amount of silver present in the zeolite surface and consequently changed the silver release profile in an of simulated exudate fluid. The kinetic models suggested that the release of the silver was not primarily governed by Fick's law of diffusion.
\end{abstract}

Keywords: impregnation, ion-exchange, burn dressings, type Y zeolite.

\section{Introdução}

Os cremes tópicos de sufadiazina de prata têm sido longamente utilizados como principal gerenciador de feridas em pacientes com sérias queimaduras que são especialmente suscetíveis a infecções. No entanto, as desvantagens em seus usos incluem manchas na pele e toxicidade, além de necessitar frequente remoção e reaplicação da sulfadiazina de prata, ocasionando pseudo-cicatrizes, dor e trauma no paciente queimado ${ }^{[1]}$. Nesta perspectiva, uma alternativa é a utilização de curativos à base de filmes de biopolímeros, como, por exemplo, a quitosana. A própria estrutura química da quitosana, similar à estrutura do ácido hialurônico, reforça a indicação do uso deste biopolímero como agente cicatrizador e reparador de feridas e de queimaduras, pois, a quitosana é capaz de aumentar as funções de células inflamatórias como os leucócitos polimorfonucleares e macrófagos, promovendo organização celular e atuando no reparo de feridas amplas, além de ser um agente antimicrobiano eficaz contra bactérias gram-positivas e negativas ${ }^{[2,3]}$. Devido a estas propriedades, a quitosana pode ser moldada na forma de filmes ou membranas para ser utilizada como curativos de 
feridas e de queimaduras ou como molde para enxerto de pele, agente hemostático e material para sutura cirúrgico ${ }^{[4]}$.

Uma vantagem de se utilizar um biopolímero é que este pode ser utilizado como um filme onde podem ser incorporadas zeólitas trocadas com prata para a liberação controlada dos íons prata diretamente na ferida e na proporção necessária para atuar contra bactérias e promover a rápida cicatrização. Assim, um curativo ideal, pode combinar as propriedades da quitosana com as propriedades antimicrobianas da prata com liberação controlada através do auxílio de uma zeólita obtendo um curativo com propriedades excelentes de aceleração da cicatrização, propriedades antifúngicas, antibacterianas e ainda recobrimento da área lesionada sem ocasionar ao paciente dor e desconforto.

Estruturamente, as zeólitas são polímeros cristalinos baseados em um arranjo tridimensional de tetraedros $\mathrm{TO}_{4}\left(\mathrm{SiO}_{4}\right.$ ou $\left.\mathrm{AlO}_{4}^{-}\right)$ligados por átomos de oxigênio para formar subunidades e enormes redes constituídas por blocos idênticos. Os tetraedros se arranjam em anéis que por sua vez são combinados para formar canais e cavidades regulares e uniformes ${ }^{[5]}$.

Muitos autores estudaram zeólitas trocadas com prata a fim de se verificar o mecanismo de liberação da prata para o meio e sua consequente atividade antimicrobiana contra muitas estirpes como, por exemplo, Escherichia coli, Staphylococcus aureus e Pseudomonas aeruginosa ${ }^{[6-8]}$. Muitos estudos foram realizados adicionando zeólitas trocadas com prata em filmes poliméricos para aplicação como embalagens ativas para alimentos ou para curativos, como por exemplo, zeólitas com prata adicionadas em filmes de polietileno ${ }^{[9]}$ e polipropileno ${ }^{[10]}$. No entanto, a incorporação de zeólitas trocadas com prata adicionadas em filmes poliméricos de quitosana para a obtenção de um curativo ideal ainda não foi muito investigado.

Neste contexto, o objetivo deste trabalho foi o desenvolvimento de novos materiais poliméricos com Ag-zeólita para a substituição do curativo convencional de sulfadiazina de prata no tratamento de queimaduras. A incorporação da prata nas zeólitas foi realizada por duas metodologias diferentes, troca iônica e impregnação úmida a fim de avaliar os efeitos dos dois diferentes métodos nas características físico-química dos materiais finais sintetizados.

\section{Materiais e Métodos}

\subsection{Materiais}

A zeólita de partida utilizada neste trabalho foi a $\mathrm{NaY}$, cedida pela Fábrica Carioca de Catalisadores (FCC). Como sal precursor antibacteriano foi utilizado o nitrato de prata P.A. $\left(\mathrm{AgNO}_{3}\right)$ da marca Nuclear. Para a síntese dos filmes poliméricos foi utilizada quitosana com grau de desacetilação igual a $82 \%$, produzida pela empresa Polymar (Fortaleza, Brasil).

\subsection{Procedimento de troca iônica e impregnação}

A troca iônica foi realizada em batelada segundo o procedimento proposto por Silva e Fernandes-Machado ${ }^{[11]}$. Solubilizou-se o nitrato de prata em quantidade necessária para produzir o catalisador no teor desejado de fase ativa de
$5 \%$ em água deionizada, na qual a razão $\mathrm{Ag}^{+} / \mathrm{Na}^{+}$foi igual a 2 . As condições para a realização da troca-iônica foram: pH entre 5 e 6 , temperatura de $80^{\circ} \mathrm{C}$, agitação branda e tempo de troca de $30 \mathrm{~min}$. Após, seco em estufa a $100{ }^{\circ} \mathrm{C}$ por $12 \mathrm{~h}$, sendo o material resultante denominado de AgY-TI.

A zeólita impregnada com prata foi obtida solubilizando-se o nitrato de prata (quantidade necessária para produzir o catalisador no teor desejado de fase ativa 5\%) em água. A suspensão obtida foi transferida para um evaporador rotativo e mantido sobre vácuo a $80{ }^{\circ} \mathrm{C}$ até que todo o conteúdo de água evaporasse. Secou-se em estufa a $100^{\circ} \mathrm{C}$ por $12 \mathrm{~h}$ com a finalidade de retirar qualquer quantidade de água remanescente. $\mathrm{O}$ material foi calcinado a $773 \mathrm{~K}$ por $5 \mathrm{~h}$ (rampa de aquecimento de $3 \mathrm{~K} / \mathrm{min}$.). Esta amostra foi denominada de AgY-I.

\subsection{Preparo dos filmes poliméricos}

A quitosana em pó foi solubilizada em solução aquosa contendo ácido acético adicionado em quantidade estequiométrica mais $50 \%$ em excesso, baseada no grau de desacetilação e massa de amostra, sendo mantida sobre agitação magnética durante $2 \mathrm{~h}$. Como agente plastificante foi utilizado glicerol $25 \%$ (g de glicerol/g massa seca de quitosana). A solução de quitosana contendo zeólita foi preparada de maneira similar à apresentada anteriormente, porém, adicionou-se $0,2 \%$ de zeólita em relação à massa total de solução $(\mathrm{m} / \mathrm{m})$ juntamente com o glicerol e homogeneizou-se a solução resultante sob agitação mecânica vigorosa a $1500 \mathrm{rpm}$ por $2 \mathrm{~h}$. Os filmes foram preparados dispersando a solução em placas de Petri de polietileno, estas submetidas à secagem em estufa com circulação forçada de ar à $37^{\circ} \mathrm{C}$ por $24 \mathrm{~h}$ (Tecnal, Brasil).

\subsection{Caracterização}

\subsubsection{Ressonância Magnética Nuclear (RMN)}

Para a determinação da razão Si/Al estrutural da zeólita $\mathrm{NaY}$ foi realizada a análise de ressonância magnética nuclear (RMN). Os experimentos de RMN no estado sólido foram realizados em equipamento Varian, modelo Mercury plus 300 , na qual operou a $59,6132 \mathrm{MHz}$ para a frequência do núcleo de ${ }^{29} \mathrm{Si}$ e $78,186 \mathrm{MHz}$ para o núcleo de ${ }^{27} \mathrm{Al}$, equipado com sonda de sólidos CP/MAS $7 \mathrm{~mm}$.

\subsubsection{Fluorescência de raios $X$ por reflexão total (TXTF)}

A análise de fluorescência de raios X por reflexão total (TXRF) foi utilizada para a determinação da quantidade de prata nas zeólitas após o procedimento de troca iônica e impregnação utilizando o equipamento S2 PICOFOX. As amostras foram previamente preparadas e fixadas em refletores de quartzo, os quais foram irradiados por $800 \mathrm{~s} \mathrm{sob}$ reflexão total por um feixe de raios $\mathrm{X}$ de $20 \mathrm{keV}$, extraído da fonte radioativa de Molibdênio, para determinação da concentração de prata presente nas amostras.

\subsubsection{Microscopia Eletrônica de Varredura (MEV)}

As micrografias das amostras zeolíticas foram obtidas por meio de um microscópio eletrônico de varredura (Shimadzu SS-550). A avaliação da estrutura final dos filmes de quitosana pura ou com Ag-zeólitas foi realizada sobre a superfície longitudinal e na área transversal de 
ruptura, após fratura criogênica utilizando nitrogênio líquido. Foi utilizado um microscópio eletrônico de varredura 440i (LEO Electron Microscopy Ltda.).

\subsubsection{Difração de Raios-X (DRX)}

As análises de difração de raios $\mathrm{X}$ dos filmes poliméricos e das zeólitas foram realizadas utilizando um difratômetro Bruker D8 Advance. Utilizou-se uma fonte de radiação de emissão de cobre $(\mathrm{CuK \alpha}, 0,24 \%$ min na varredura, $40 \mathrm{kV}$ e $50 \mathrm{~mA}$ ) e varredura de $2 \theta$ variando na faixa 4 a $50^{\circ}$. Para identificação das fases presentes foi utilizado o banco de dados do software JCPDS.

\subsubsection{Propriedades mecânicas}

As propriedades mecânicas foram medidas baseadas na metodologia padronizada ASTM D-882 ${ }^{[12]}$ utilizando um texturômetro TA.XT2 (Stable Microsystems, Inglaterra). Através desta análise foram determinados a porcentagem de elongação, módulo de Young e tensão de ruptura.

\subsubsection{Permeação ao vapor d'água (PVA)}

Para a determinação da permeação ao vapor d'água (PVA) utilizou-se o método padronizado ASTM E96-95 $5^{[13]}$. O filme foi fixado em frascos contendo sílica e acondicionados em dessecador com UR controlada igual a $75 \%$. O ganho de massa dos frascos foi acompanhado durante $40 \mathrm{~h}$. Foram realizadas 5 repetições para cada filme.

\subsubsection{Cinética de liberação da prata in vitro}

O perfil de liberação de prata dos filmes foi realizado em solução simulada de exsudato de ferida. Esta solução contém $142 \mathrm{mmol} / \mathrm{L}$ de íons sódio e $2,5 \mathrm{mmol} / \mathrm{L}$ de íons cálcio que representa as concentrações de sais observadas nos fluidos das feridas e do soro. A prata liberada deste meio foi analisada por espectroscopia de absorção atômica (SpectrAA modelo 50B- VARIAN) utilizando lâmpada de cátodo oco $(\lambda=328 \mathrm{~nm})$ e uma mistura de ar e acetileno.

\subsubsection{Análise estatística}

Foram realizadas análises estatísticas utilizando-se o software livre Action ${ }^{\circledast}$ (2014). As diferenças significativas entre as médias foram analisadas utilizando o Teste de Tukey, com nível de significância $\mathrm{p} \leq 0,05$.

\section{Resultados e Discussão}

Utilizando os princípios da deconvolução de Euler e com o auxílio do software OriginPro foi possível decompor precisamente os quatro picos coordenados da Figura $1 \mathrm{a}$, a fim de quantificar e identificar estruturalmente diferentes ambientes do silício, e com isso determinar a razão silício/alumínio estrutural. Assim, o espectro de RMN de ${ }^{29} \mathrm{Si}$ da zeólita $\mathrm{NaY}$ revelou a presença dos ambientes $\mathrm{Si}(3 \mathrm{Al}), \mathrm{Si}(2 \mathrm{Al}), \mathrm{Si}(1 \mathrm{Al})$ e $\mathrm{Si}(0 \mathrm{Al})$, referentes a $-89,27 ;-93,77 ;-99,10$; e $-104,61$ ppm, respectivamente, como encontrado na literatura ${ }^{[5,14]}$. A razão molar de Si/Al estrutural determinada foi de 2,54. Este valor está coerente com o relatado por Weitkamp e Puppe $^{[15]}$ o qual a razão Si/Al deve estar compreendida na faixa de 1,5 a 3. Quanto aos espectros de MAS-RMN de ${ }^{27} \mathrm{Al}$ (Figura 1b) da amostra NaY, observa-se uma linha de ressonância em 59,02 ppm, correspondendo ao sinal

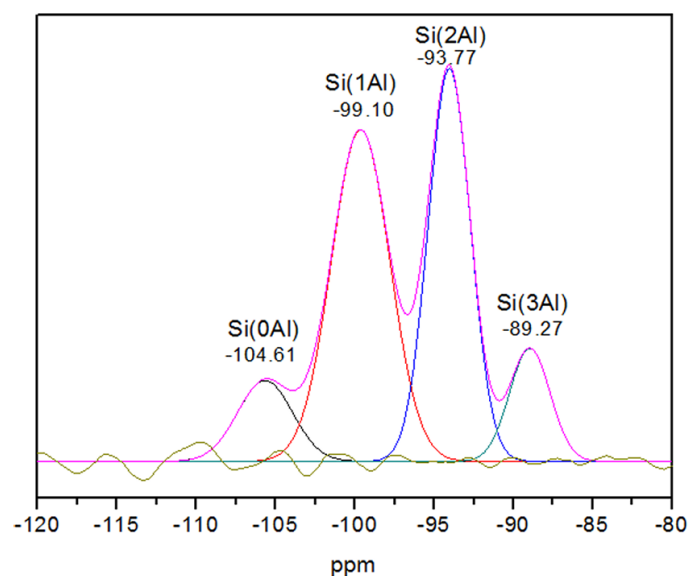

(a)

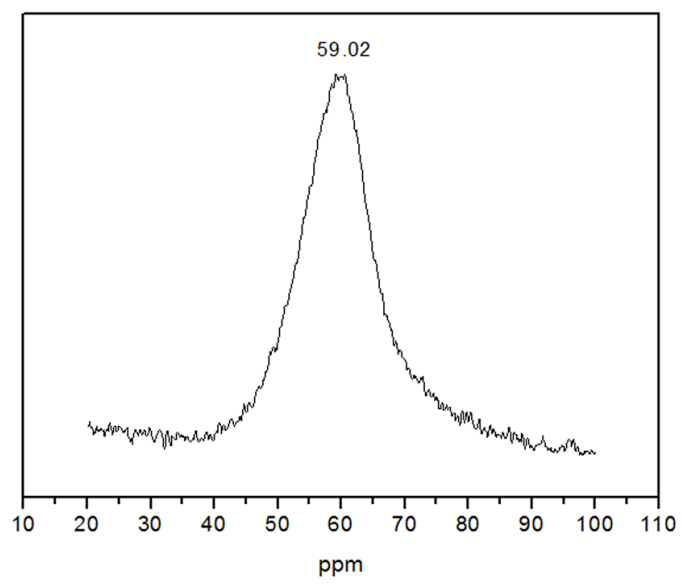

(b)

Figura 1. Espectros de RMN de (a) ${ }^{29} \mathrm{Si} \mathrm{e} \mathrm{(b)}{ }^{27} \mathrm{Al}$.

das espécies de alumínio tetraédrico. A ausência de pico referente a alumínio octaédrico, sinal aproximadamente em 0 ppm, indica a inexistência de alumínio extra rede, resultados também obtidos por Guerra et al. ${ }^{[16]}$.

A porcentagem mássica de prata obtida por TXRF foi de $20,25 \%$ para a amostra AgY-TI, o que representa $44 \%$ de sódio trocado e 7,99\% para a amostra AgY-I, indicando que houve uma impregnação de cerca de $60 \%$ a mais de prata. Esse excesso de prata pode ser explicado pela alta higroscopicidade da zeólita, que sem um extremo cuidado de secagem prévia e tempo de pesagem, leva a um material com teor de umidade não desejado. Para a troca iônica, o nitrato de prata (5\%) foi solubilizado em água deionizada com uma razão $\mathrm{Ag}^{+} / \mathrm{Na}^{+}$igual a 2 . A solução de nitrato de prata e zeólita foi filtrada e lavada 3 vezes, sendo que a primeira lavagem consistiu-se de $70 \%$ do volume da suspensão de troca iônica em água deionizada além da mesma quantidade de sal utilizada na troca. Em função do pequeno raio iônico da prata, durante a lavagem houve troca iônica, por isso a quantidade de prata é quatro vezes maior do que a quantidade estequiométrica supostamente necessária para a troca de todo o sódio da zeólita, justificando o alto teor obtido pela análise de TXRF. 
Os picos característicos de zeólita FAU (Figura 2) em $2 \theta=6,24^{\circ}, 15,70^{\circ}, 23,69^{\circ}, 27,08^{\circ}$ e $31,43^{\circ}$ são atribuídos, respectivamente, aos planos cristalográficos [111], [331], [622], [624], [804] e foram observados tanto na zeólita de partida (NaY) como nas amostras submetidas aos procedimentos de troca iônica (AgY-TI) e impregnação (AgY-I).

A semelhança entre os diagramas das zeólitas de partida e as modificadas após o processo de troca com prata ou impregnação revela que estes processos não promovem qualquer modificação estrutural na zeólita ${ }^{[7,9,17-20]}$. Não foram encontrados os picos característicos da prata metálica em $2 \theta=38,21^{\circ}, 44,51^{\circ}, 64,51^{\circ}$ e $77,51^{\circ}$. Esse resultado indica uma boa troca ionica na amostra AgY-TI e que durante a calcinação não houve formação de aglomerados de $\operatorname{Ag}_{2} \mathrm{O}$. Já na amostra impregnada, o baixo teor de prata e a alta dispersão dos critalitos explica sua não identificação. Inúmeros autores incorporaram diversos teores de prata na estrutura zeolítica por diversas metodologias diferentes e muitos deles também não verificaram a presença de cristais de prata em seus diagramas ${ }^{[7-9,19,21-23]}$

Sabendo-se que a região de $2 \theta$ entre $10^{\circ}$ e $20^{\circ}$ é relacionada com a localidade dos cátions na estrutura zeolítica, observa-se então, que em todas as amostras, houve uma redução da maior parte dos picos característicos, indicando uma redistribuição dos cátions de balanceamento de carga na estrutura interna da zeólita ${ }^{[7,18,24]}$.

A Figura 3 ilustra a comparação entre os filmes de quitosana pura, filmes de quitosana com zeólita incorporada e a zeólita.

Observa-se que a incorporação de material zeolítico na matriz polimérica dos filmes promove o aparecimento de picos característicos das zeólitas nos diagramas dos filmes sintetizados.

A cristalinidade relativa da quitosana nos filmes com AgY-TI e AgY-I foi comparada com o filme de quitosana puro, o qual foi definido como sendo de $100 \%$, utilizando a metodologia baseada no método ASTM D-3906-80 ${ }^{[25]}$. Para comparação foram utilizados dois picos de difração característicos da quitosana, localizados em $2 \theta=11,4^{\circ}$ e

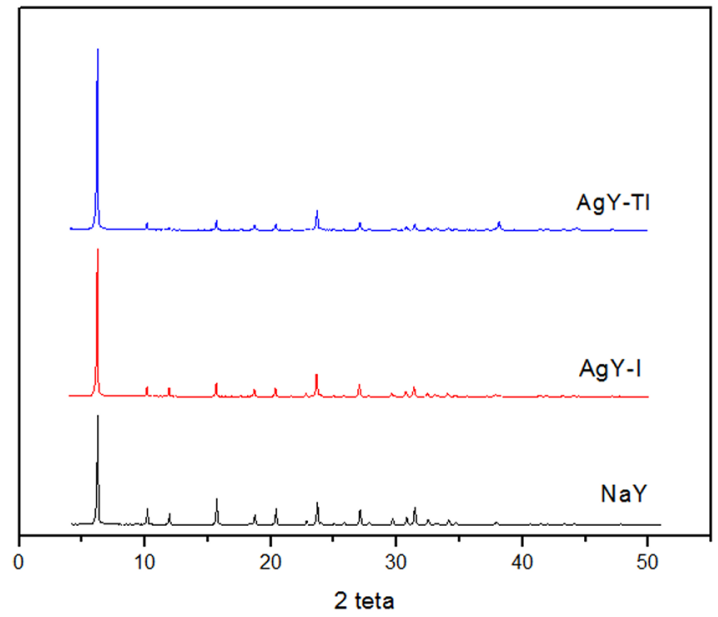

Figura 2. Diagramas de DRX da zeólitas AgY-TI, AgY-I e NaY. $20,1^{\circ}$, referentes ao cristal I $\left(a=7.76 \mathrm{~A}^{\circ}, b=10.91 \mathrm{~A}^{\circ} \mathrm{e}\right.$ $\left.c=10.30 \mathrm{~A}^{\circ}\right)$ e cristal II $\left(a=4.4 \mathrm{~A}^{\circ}, b=10.0 \mathrm{~A}^{\circ}\right.$ e $\left.c=10.3 \mathrm{~A}^{\circ}\right)$, respectivamente, ambos ortorrômbicos ${ }^{[26]}$

Houve diminuição das intensidades relativas dos picos característicos da quitosana após a incorporação de zeólita, sendo de $51,65 \%$ e $82,49 \%$ para as amostras AgY-TI e AgY-I, respectivamente. A presença de zeólitas no filme interferiu no empacotamento ordenado das cadeias de quitosana tanto por efeitos estéricos como também pela formação de ligações de hidrogênio entre os grupos - $\mathrm{OH}$ superficiais das zeólitas e grupos $-\mathrm{NH}_{2} \mathrm{e}-\mathrm{OH}$ da quitosana, resultando na diminuição da cristalinidade da quitosana para ambas as amostras e o aparecimento de picos característicos de zeólita nos filmes sintetizados ${ }^{[27]}$.

A Figura 4 ilustra as micrografias da zeólita $\mathrm{NaY}$ antes e após o procedimento de troca iônica e impregnação com nitrato de prata.

Pode-se observar que o procedimento de troca iônica e de impregnação não modifica a morfologia da zeólita de partida. $\mathrm{O}$ tipo de procedimento adotado não altera o

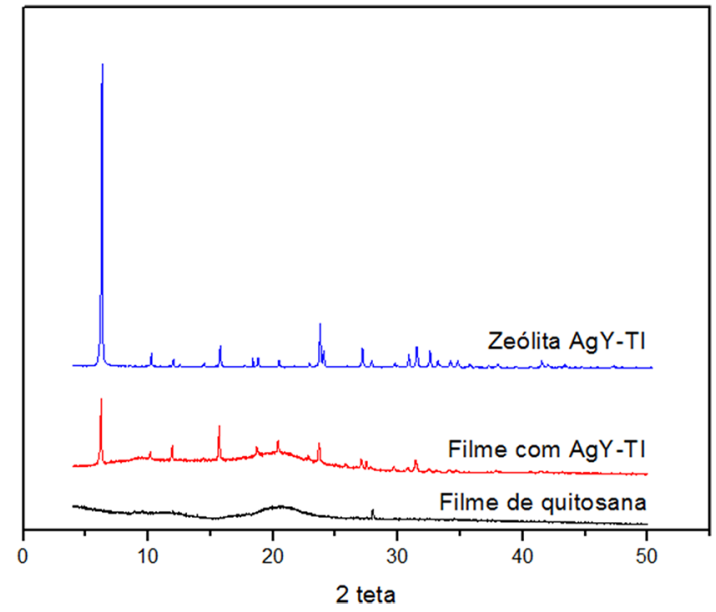

(a)

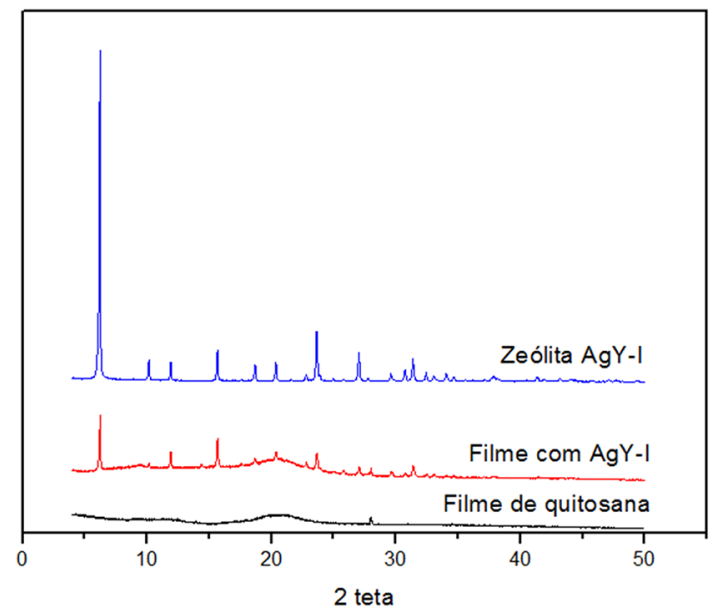

(b)

Figura 3. Diagramas dos filmes poliméricos de quitosana pura, zeólita e filme com zeólita para as amostras (a) AgY-TI e (b) AgY-I. 


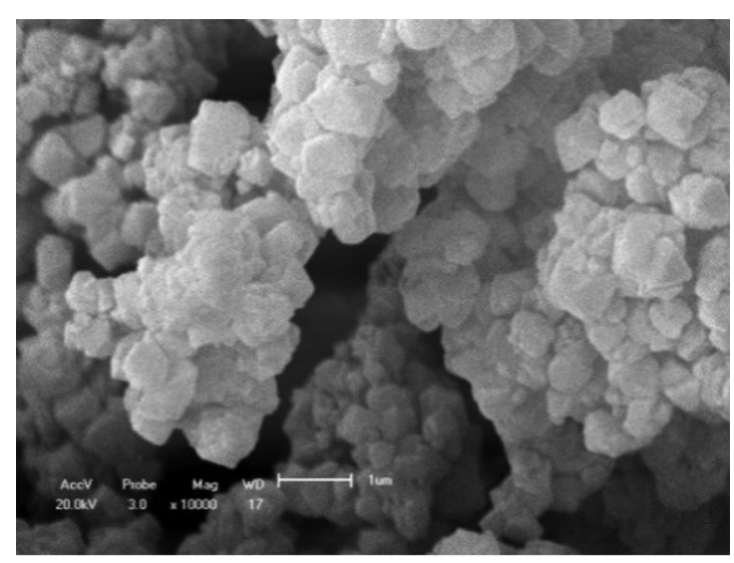

(a)

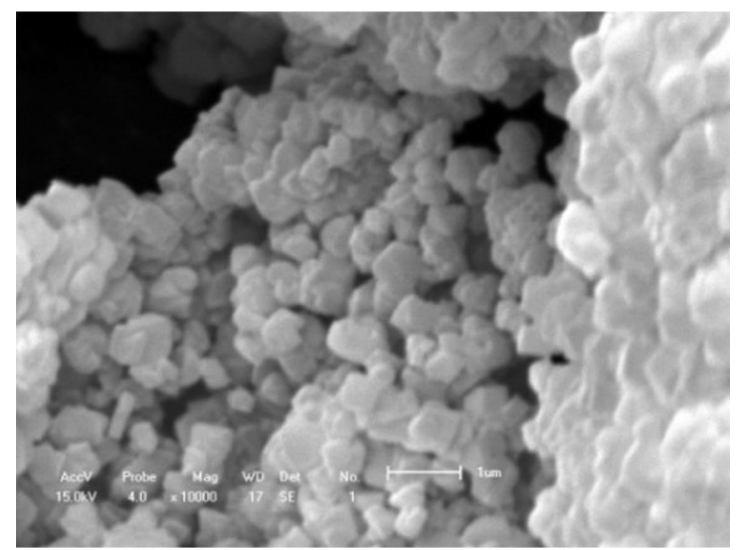

(b)

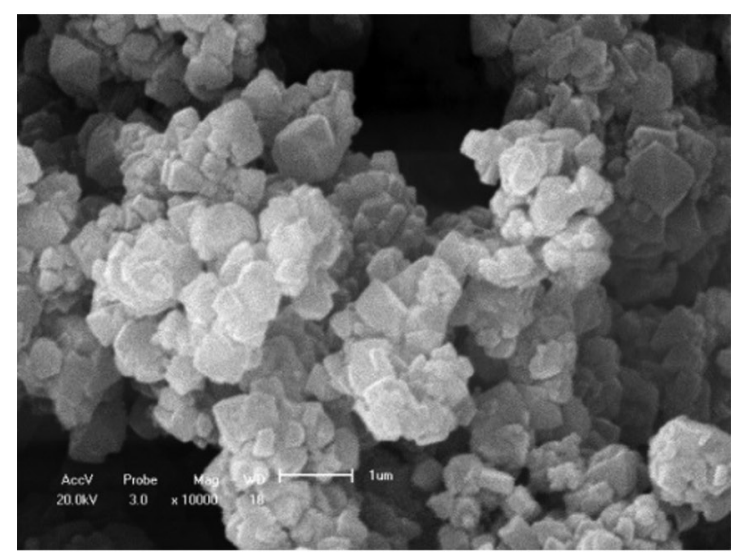

(c)

Figura 4. Micrografias das zeólitas (a) NaY, (b) AgY-TI e (c) AgY-I. (aumento de 10.000x).

tamanho médio do grão apresentando tamanho de partícula médio entre 0,77 e $0,80 \mu \mathrm{m}$. Esse resultado corrobora com o de DRX, pois não foram encontrados aglomerados que poderiam ser atribuídos à prata.

Outros autores também observaram que zeólitas com e sem prata apresentam aparência muito similar, formas poliédricas regulares e o mesmo tamanho de partícula ${ }^{[9,17,23]}$.
As micrografias obtidas por microscopia eletrônica de varredura (MEV) da superfície dos filmes poliméricos com aumento de 500 vezes (micrografia da esquerda) e da seção transversal (micrografia da direita) das mesmas com um aumento de 3000 vezes são apresentadas na Figura 5.

Observa-se que o filme de quitosana pura (Figura 5) apresentou-se como uma matriz compacta, sem defeitos apreciáveis e ausência de macroporos, resultados estes também condizentes com os obtidos por outros autores ${ }^{[28-32]}$.

A partir da micrografia da seção transversal dos filmes com zeólitas (Figura 5b e Figura 5c), observou-se que em todas as amostras houve alguma aglomeração das partículas de zeólita, indicando que os diâmetros das partículas eram demasiadamente grandes, e provável sedimentação das mesmas. Assim, ocorreu a separação de fases da zeólita e da quitosana, formando um filme compósito que se constituiu de duas fases bem distintas, uma orgânica de quitosana e uma inorgânica de zeólita. Wang et al. ${ }^{[30]}$ também incorporaram zeólita beta em filmes de quitosana e verificaram que para partículas com diâmetro entre 3 e $5 \mu \mathrm{m}$ pode haver a sedimentação da zeólita, o que influencia diretamente nas propriedades de barreira e superficiais dos filmes poliméricos.

Na Tabela 1 são apresentadas as propriedades mecânicas obtidas para os filmes poliméricos sintetizados neste trabalho. A incorporação de zeólita NaY e zeólita impregnada (AgY-I) não alterou significativamente o módulo de Young e a tensão de ruptura quando comparado com o filme de quitosana pura, diferentemente do obtido pela amostra submetida ao procedimento de troca iônica, na qual apresentou diferença significativa quando comparada com as outras amostras deste estudo.

Como observado na análise de TXRF, a zeólita AgY-I apresentou uma porcentagem de prata muito menor do que a amostra AgY-TI, indicando que a presença de uma maior quantidade de prata pode influenciar significativamente nas propriedades mecânicas dos filmes provavelmente devido às interações eletrostáticas entre os polímeros/zeólitas/prata metálica, restringindo a mobilidade das cadeias poliméricas ${ }^{[26,33]}$.

A diminuição da porcentagem e elongação para todos os filmes poliméricos com zeólita quando comparado com o filme de quitosana pura pode ser devido à presença de grumos de zeólita, nos quais causaram uma desorganização local no empacotamento das cadeiras poliméricas da quitosana fazendo com que a estrutura polimérica se rompesse mais facilmente próximos aos pontos onde os grumos de zeólita se encontram inseridos. Os grumos de zeólita podem ser observados nas micrografias transversais dos filmes poliméricos com zeólita. Também pela análise de MEV dos filmes sintetizados (Figura 5b e Figura 5c), observa-se a presença de pequenas fissuras em todos os filmes com zeólitas. Como na micrografia da seção transversal estas não se encontram presentes nos filmes de quitosana pura, sugere-se que nos demais filmes a presença destas fissuras e falhas facilitam o rompimento do filme reduzindo consequentemente a porcentagem de elongação.

A presença de glicerol nos filmes poliméricos resultou em filmes com melhor maleabilidade (menor módulo de Young) e melhor flexibilidade (maior porcentagem de elongação) do que os filmes confeccionados por Santos et al. ${ }^{[34]}$ que 


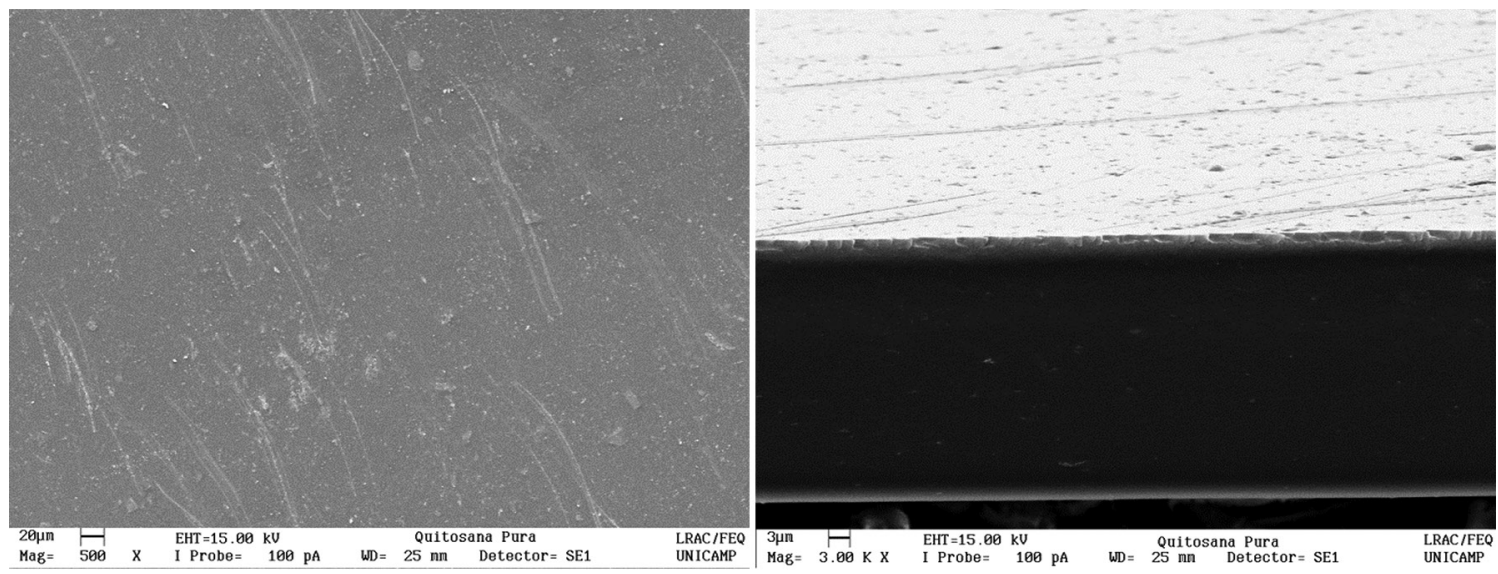

(a) Filme de quitosana pura

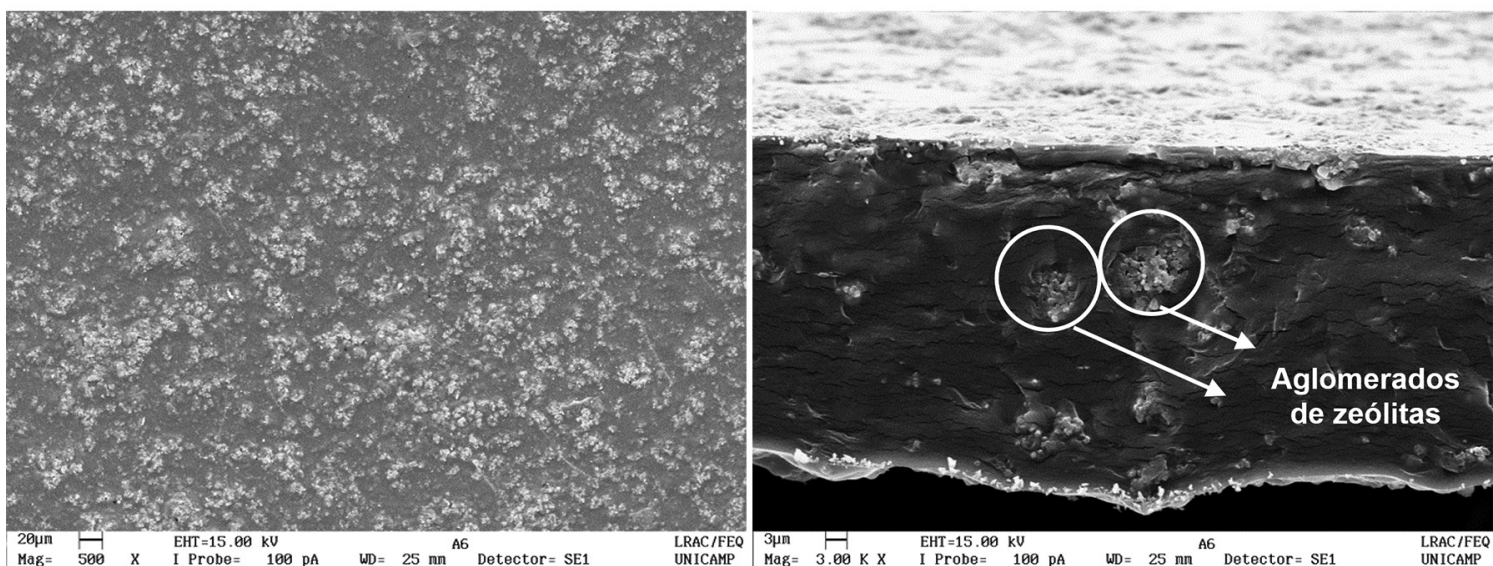

(b) Filme com AgY-TI
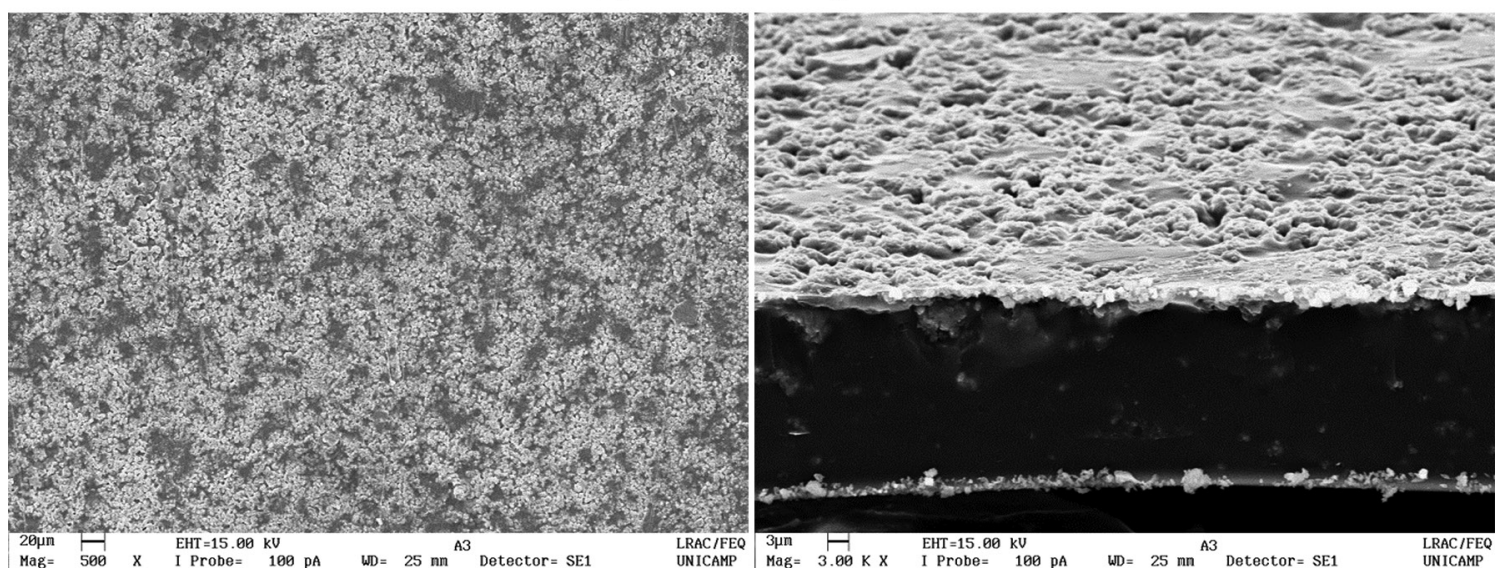

(c) Filme com AgY-I

Figura 5. Micrografias dos filmes, à esquerda imagem da superfície longitudinal e à direita imagem da área transversal de ruptura.

adicionaram zeólita ZSM-5 em filmes de quitosana sem a presença de glicerol. Fiori et al. ${ }^{[35]}$ também observaram que a adição de plastificantes melhorou a flexibilidade do filmes de quitosana e que a adição de argila bentonita na matriz polimérica resultou em um filme mais resistente.

Na Tabela 2 são apresentadas os valores para a taxa de permeação ao vapor de água (TPVA) e a permeação ao vapor de água (PVA) dos filmes de quitosana. Não se observou diferença significativa entre os filmes de quitosana pura e os com zeólitas.

A pele humana normal possui permeabilidade ao vapor d'água (PVA) de $0,204 \pm 0,012 \mathrm{~g} / 10 \mathrm{~cm}^{2} / 24 \mathrm{~h}$, ou seja, a pele perde $0,204 \mathrm{~g}$ de água em uma área de $10 \mathrm{~cm}^{2}$ durante $24 \mathrm{~h}$. Para a pele com lesão por queimaduras de primeiro grau ou 
Tabela 1. Propriedades mecânicas dos filmes poliméricos.

\begin{tabular}{|c|c|c|c|}
\hline Filme de quitosana & Módulo de Young (MPa)* & Tensão de ruptura (MPa)* & Porcentagem de elongação (\%)* \\
\hline Pura (sem zeólita) & $4,17 \pm 0,97^{\mathrm{a}}$ & $13,26 \pm 0,71^{\mathrm{a}}$ & $19,60 \pm 0,38^{\mathrm{a}}$ \\
\hline $\mathrm{NaY}$ & $5,36 \pm 0,99^{\mathrm{a}}$ & $14,87 \pm 1,91^{\mathrm{a}}$ & $12,52 \pm 1,32^{\mathrm{c}}$ \\
\hline AgY-TI & $11,00 \pm 0,81^{\mathrm{b}}$ & $27,83 \pm 1,18^{\mathrm{b}}$ & $8,94 \pm 1,70^{\mathrm{b}}$ \\
\hline AgY-I & $5,07 \pm 0,39^{\mathrm{a}}$ & $15,39 \pm 2,08^{\mathrm{a}}$ & $10,35 \pm 2,45^{b}$ \\
\hline
\end{tabular}

*Diferentes sobrescritos na mesma coluna indicam diferenças significativas entre as formulações $(p<0,05)$.

Tabela 2. Taxa de permeação ao vapor d'água.

\begin{tabular}{ccc}
\hline Filme de Quitosana & TPVA $\left(\mathbf{g} / \mathbf{1 0} \mathbf{c m}^{\mathbf{2} . \mathbf{2 4 h}}\right)^{*}$ & PVA $\left.\mathbf{( 1 0 ^ { - 1 1 }} \mathbf{g} / \mathbf{m . s . P a}\right)^{*}$ \\
\hline Pura (sem zeólita) & $0,46 \pm 0,03^{\mathrm{a}}$ & $8,33 \pm 0,46^{\mathrm{a}}$ \\
AgY-TI & $0,49 \pm 0,03^{\mathrm{a}}$ & $8,46 \pm 0,42^{\mathrm{a}}$ \\
AgY-I & $0,50 \pm 0,01^{\mathrm{a}}$ & $9,26 \pm 0,02^{\mathrm{a}}$ \\
NaY & $0,49 \pm 0,05^{\mathrm{a}}$ & $9,17 \pm 0,81^{\mathrm{a}}$ \\
\hline
\end{tabular}

*Diferentes sobrescritos na mesma coluna indicam diferenças significativas entre as formulações $(p<0,05)$.

quando a ferida está formando o tecido de granulação, as permeabilidades são $0,279 \pm 0,026$ e $5,138 \pm 0,202 \mathrm{~g} / 10 \mathrm{~cm}^{2} / 24 \mathrm{~h}$, respectivamente ${ }^{[36]}$. Em relação à permeabilidade ao vapor d'água de um curativo ideal ${ }^{[37,38]}$, este deve possuir permeabilidade ao vapor d'água de $1,200 \mathrm{~g} / 10 \mathrm{~cm}^{2} / 24 \mathrm{~h}$ enquanto que para Wu et al. ${ }^{[39]}$ e Mi et al. ${ }^{[40]}$ o ideal é de $2,500 \mathrm{~g} / 10 \mathrm{~cm}^{2} / 24 \mathrm{~h}$. Kim et al. ${ }^{[41]}$ encontraram valores de permeabilidade de 1,938 a 2,212 g/10 cm2/24 h, enquanto outros autores encontraram permeabilidades mais baixas semelhantes ao obtido neste trabalho, como Wang et al. ${ }^{[42]}$ e Remuñán-López e Bodmeier ${ }^{[43]}$ que obtiveram, $0,560-0,658 \mathrm{~g} / 10 \mathrm{~cm}^{2} / 24 \mathrm{~h} \mathrm{e}$ 0,288-1,008 g/10 $\mathrm{cm}^{2} / 24 \mathrm{~h}$, respectivamente.

Os valores de TPVA dos filmes sintetizados variaram entre 0,46 e $0,50 \mathrm{~g} / 10 \mathrm{~cm}^{2} / 24 \mathrm{~h}$ e também não mostraram diferença significativa entre eles. Observa-se que muitos curativos disponíveis comercialmente apresentam valores ainda mais baixos variando entre 0,1360 e $0,476 \mathrm{~g} / 10 \mathrm{~cm}^{2} / 24 \mathrm{~h}$ para os curativos Comfeel $^{\circledR}$, Dermiflex ${ }^{\circledR}$, Granuflex $\mathrm{E}^{\circledR}$, IntraSite $^{\circledR}$, Restore $\mathrm{Cx}^{\circledR}$, Tegasorb ${ }^{\circledR}$ e Bioclusive $^{\circledR[44]}$.

A Figura 6 apresenta os perfis de liberação de prata a partir dos filmes poliméricos sintetizados.

O filme com AgY-TI apresentou uma taxa de liberação de prata maior do que o filme com AgY-I. Este fato é decorrente da maior concentração de prata na zeólita AgY-TI observada pela análise elementar de TXRF. Boschetto et al. ${ }^{\left[{ }^{[]}\right.}$ observaram também que quanto maior a quantidade de prata na superfície da zeólita, maior é a quantidade de prata lixiviada a partir de filmes de poliestireno.

Observa-se que a quantidade de prata liberada é muito baixa, o que poderia ser um fato positivo em relação à sua citotoxicidade e mesmo após dois dias de liberação ainda estava ocorrendo a liberação da prata, isto é, a quantidade de prata liberada ainda não havia se tornado constante para a amostra na qual a prata havia sido incorporada à zeólita pelo procedimento de troca iônica, AgY-TI. Para a zeólita impregnada com prata, já se esperava uma menor concentração de prata na solução, justamente porque o procedimento de impregnação visa a fixação da prata no suporte através da decomposição do sal $\mathrm{AgNO}_{3}$.

Todos os filmes sintetizados apresentaram uma liberação de prata menor que $1 \mathrm{ppm}$. No entanto, Walker et al. ${ }^{[45]}$

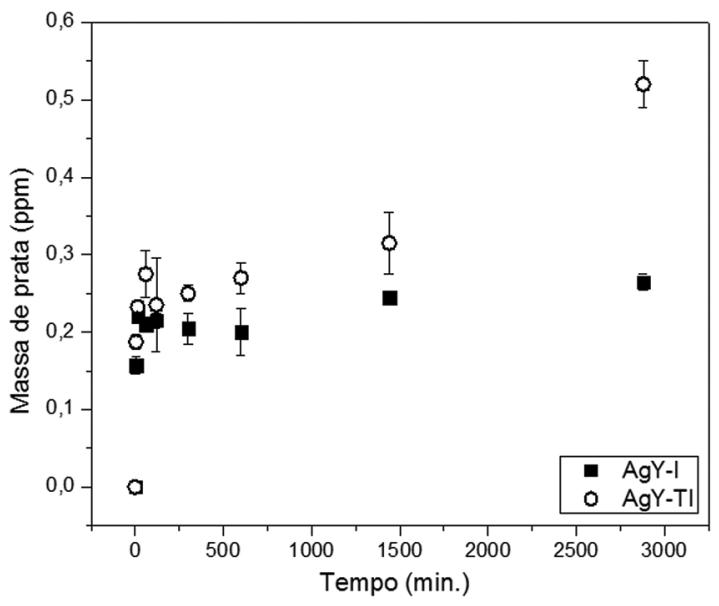

Figura 6. Perfis de liberação da prata a partir dos filmes poliméricos.

verificaram que os curativos comerciais Ancticoat ${ }^{\circledR}$ e Aquacel-Ag Hydrofiber ${ }^{\circledR}$ lixiviam 55 e 1 ppm de Ag $^{+}$, respectivamente. Ou seja, Aquacel-Ag Hydrofiber ${ }^{\circledR}$ libera tão pouca prata quanto os filmes sintetizados neste trabalho. No entanto, a baixa concentração de prata obtida também foi verificada por outros autores que realizaram o experimento tanto em salmoura como em fluido exsudato de ferimento e observaram que as concentrações de prata iônica caem para 1 ppm em todos os $\operatorname{casos}^{[45,46]}$.

Em termos de perfil de liberação, o filme polimérico com AgY-I apresentou um perfil de saturação, ou seja, a quantidade máxima de prata liberada é atingida em cerca de $0,25 \mathrm{ppm}$, onde é provável que toda a prata passível de liberação já tenha sido liberada. Por outro lado, a AgY-TI não atinge esta saturação, apresentando um perfil de liberação lento, o que é bastante desejável já que a prata pode ser citotóxica quando liberada no leito de queimadura em grandes quantidades rapidamente.

Optou-se por realizar esta análise em solução simulada de exsudato de ferida por ser uma solução mais próxima da situação real encontrada em uma queimadura mesmo sabendo 
que íons cloreto nesta solução podem inibir parcialmente os íons prata. O teste não foi realizado em água deionizada, pois, segundo Matsumura et al. ${ }^{[47]}$ nenhuma quantidade de prata considerável foi detectada, não simulando uma condição real, pois não há troca iônica para liberar a prata presente na estrutura da zeólita.

Os dados experimentais obtidos nos ensaios de liberação de prata a partir dos filmes poliméricos são apresentados na Figura 7 e foram ajustados a vários modelos matemáticos visando analisar o comportamento cinético do sistema. Os modelos utilizados (Tabela 3 ) foram Higuchi ${ }^{[48]}$, primeira ordem $^{[49]}$, Korsmeyer et al. ${ }^{[50]}$, Peppas e Sahlin ${ }^{[51]}$.

Os ajustes dos quatro modelos propostos foram realizados utilizando o programa OriginPro e a escolha do melhor modelo ajustado foi realizada baseada no método de análise do coeficiente de correlação $\mathrm{R}^{2}$.

A Figura 7 apresenta os ajustes dos modelos cinéticos para os filmes com AgY-I e AgY-TI, respectivamente, e a Tabela 4 apresenta os parâmetros cinéticos obtidos bem como o coeficiente de correlação de cada modelo.

Os dados experimentais não se ajustaram ao modelo cinético de Higuchi ${ }^{[48]}$ (Equação 1) pelos baixos valores de $\mathrm{R}^{2}$ obtidos. Este modelo apresenta fortes limitações na

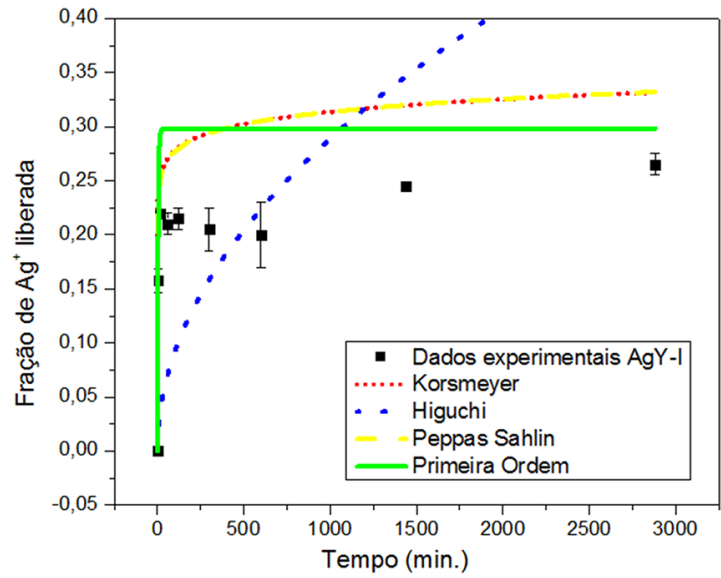

(a) AgY-I

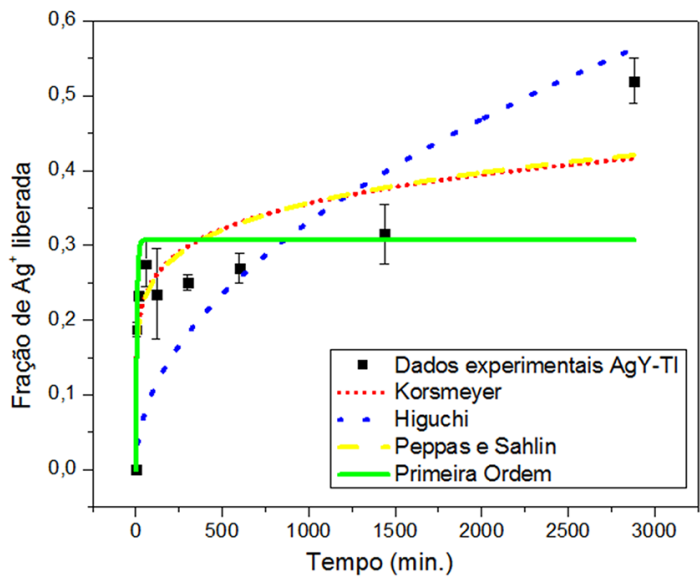

(b) AgY-TI

Figura 7. Ajuste dos modelos cinéticos para os filmes com (a) AgY-I e (b) AgY-TI. interpretação dos mecanismos de liberação controlada, justamente por ser melhor aplicável em filmes poliméricos pouco solúveis e/ou que não apresentam capacidade de intumescimento ${ }^{[52,53]}$, fatos não observados nos filmes sintetizados neste trabalho.

Apesar do coeficiente de correlação obtido pelo modelo de primeira ordem ${ }^{[49]}$ (Tabela 4) ter sido muito maior do que aquele obtido pelo modelo de Higuchi ${ }^{[48]}$, o modelo de primeira ordem não descreve a dissolução do agente ativo que está preso entre as cadeias poliméricas da quitosana, representando apenas o comportamento da droga que se encontra na superfície do filme, sendo característica de um processo de dissolução instantânea ${ }^{[54]}$.

O mecanismo proposto por Korsmeyer et al. ${ }^{[50]}$ (Equação 3) é utilizado quando o mecanismo controlador de liberação da droga não é conhecido ou quando há a combinação dos seguintes processos regidos independentemente: transporte do fármaco no interior da matriz (difusão Fickiana) e transição de um estado semirrígido a outro mais flexível, decorrente dos fenômenos de inchamento/relaxamento do filme. Segundo Peppas ${ }^{[55]}$, para esse modelo, quando $n$ for igual a 0,5 a liberação é controlada pela difusão. Quando $n$ é igual a 1, o mecanismo controlador é o intumescimento, correspondente à cinética de ordem zero. Para $0,5<n<1$, a liberação se dá por sobreposição dos dois fenômenos citados

Tabela 3. Modelos cinéticos para liberação de fármacos.

\begin{tabular}{lc}
\hline \multicolumn{1}{c}{ Modelo } & \multicolumn{1}{c}{ Equação } \\
\hline Higuchi $^{[48]}$ & $\frac{Q_{t}}{Q_{\infty}}=K_{h} \sqrt{t}$ \\
\hline Primeira ordem $^{[49]}$ & $\ln \left(\frac{Q_{t}}{Q_{\infty}}\right)=K_{1} t$ \\
\hline Korsmeyer $^{[50]}$ & $\frac{Q_{t}}{Q_{\infty}}=K_{2} t^{n}$ \\
\hline Peppas e Sahlin $^{[5]]}$ & $Q=K_{3} t^{m}+K_{4} t^{2 m}$ \\
\hline
\end{tabular}

Tabela 4. Parâmetros dos modelos ajustados.

\begin{tabular}{cccc}
\hline Modelo & Parâmetros & $\begin{array}{c}\text { Filme com } \\
\text { AgY-I }\end{array}$ & $\begin{array}{c}\text { Filme com } \\
\text { AgY-TI }\end{array}$ \\
\hline Primeira ordem $^{[49]}$ & $\mathrm{Cs}(\mathrm{mg} / \mathrm{mL})$ & 1,4907 & $\mathrm{NA}$ \\
& $\mathrm{K}_{1}$ & 0,2453 & $\mathrm{NA}$ \\
& $R^{2}$ & 0,9206 & $\mathrm{NA}$ \\
\hline Korsmeyer $^{[50]}$ & $K_{2}$ & 0,2176 & 0,1291 \\
& $\mathrm{n}$ & 0,0529 & 0,1470 \\
& $R^{2}$ & 0,9319 & 0,8036 \\
\hline Peppas e Sahlin & & 0,1602 & 0,1034 \\
& $K_{3}$ & 0,0580 & 0,0274 \\
& $K_{4}$ & 0,0406 & 0,1130 \\
& $R^{2}$ & 0,9319 & 0,8785 \\
\hline
\end{tabular}

NA indica que o modelo não se ajustou, ou seja, o coeficiente de correlação $\left(\mathrm{R}^{2}\right)$ obtido foi muito pequeno. 
ou transporte anômalo. Os dados utilizados para a estimação do parâmetro $n$ devem ser obrigatoriamente $Q_{t} / Q_{\infty}<0,6$.

Ajustando os dados experimentais ao modelo de Korsmeyer et al. ${ }^{[50]}$, os valores encontrados para o parâmetro $n$ foram ambos menores do que 0,5 indicando que o mecanismo de liberação não se deve primordialmente à difusão ${ }^{[55]}$. Valores de $n$ menores do que 0,5 são atribuídas a não-homogeneização das partículas de tendência irregular, dificultando a liberação do fármaco por difusão controlada pela Lei de Fick ${ }^{[56]}$.

Com base na Figura 7, observa-se que o modelo proposto por Peppas e Sahlin ${ }^{[51]}$ resultou em uma curva idêntica ao modelo proposto por Korsmeyer et al. ${ }^{[50]}$ para ambas as amostras. Este fato é devido ao baixo valor da constante $K_{4}$, indicando que a contribuição dos fenômenos de erosão e relaxamento são desprezíveis em ambos os filmes sintetizados neste trabalho. Assim, o modelo cinético proposto por Peppas e Sahlin ${ }^{[51]}$ também apresentou o expoente que caracteriza a cinética de liberação $(m)$ abaixo de 0,5 , o que corrobora com os resultados obtidos pelo modelo de Korsmeyer et al. ${ }^{[50]}$ indicando que a liberação da prata a partir da zeólita e do filme de quitosana não é primordialmente governada pelo mecanismo de difusão.

Neste trabalho, liberação da prata pode ter sido dificultada por esta estar presente no filme polimérico provavelmente na forma de nanopartículas de prata e estas ficarem presas ("entrapped") no filme, justificando a dificuldade da dissolução e difusão da prata para a solução simulada de exsudato de ferida.

O uso do par quitosana/prata pode levar indiretamente à formação de nanopartículas de prata pelo método clássico de produção de nanopartículas ${ }^{[57,58]}$. Neste método, agentes redutores são utilizados para reduzir os íons de prata em solução aquosa produzindo prata coloidal. Inicialmente, a redução de íons de prata $\left(\mathrm{Ag}^{+}\right)$conduz à formação de átomos de prata $\left(\mathrm{Ag}_{0}\right)$, a qual é seguida por uma aglomeração. Estes aglomerados, eventualmente, conduzem à formação das nanopartículas coloidais de prata ${ }^{[57,59]}$. Devido esta aglomeração, um agente de estabilização é utilizado no processo de síntese para evitar a agregação das nanopartículas e para controlar o tamanho do produto final[ ${ }^{60]}$. Estes estabilizadores desempenham um papel importante para controlar a formação de nanopartículas, bem como a sua estabilidade. A quitosana pode ser utilizada tanto como agente redutor como agente estabilizador para este fim, durante a síntese de nanopartículas de prata ${ }^{[58]}$.

Mesmo não sendo a proposta do trabalho, a formação de nanopartículas de prata no filme polimérico de quitosana pode ser visto como um fator positivo, uma vez que partículas do tamanho nano potencializam a atividade antimicrobiana ${ }^{[61,62]}$. Assim, tanto as nanopartículas de prata como os íons prata lixiviados a partir dos filmes poliméricos inibem microorganismos patogênicos sinergicamente.

Por mais que a hipótese de formação de nanopartículas seja válida e coerente, esta hipótese deve ser firmemente averiguada.

\section{Conclusões}

Os filmes poliméricos de quitosana com Ag-zeólita mostram-se como materiais potenciais e inovadores para o desenvolvimento de um novo curativo. O processo de troca iônica ou impregnação não modifica a morfologia das zeólitas de partida, fato este constatado pelas análises de DRX e por MEV. Os filmes com Ag-zeólitas apresentaram-se mais opacos, com aglomerações de zeólitas na superfície do filme e mais rígidos, alterações que puderam ser observadas nas análises de MEV e de propriedades mecânicas, respectivamente. A amostra AgY-TI não atinge um perfil de saturação de liberação de prata, apresentando um perfil de liberação lento, o que é bastante desejável já que a prata pode ser citotóxica, ressaltando o bom desempenho da utilização de zeólita em termos de liberação controlada de prata no meio. A hipótese de formação de nanopartículas justifica a baixa liberação de prata na solução simulada de exsudato de ferida e por meio de modelos matemáticos cinéticos foi constatado que a liberação de prata a partir da zeólita/filme polimérico não é governada primordialmente pelo mecanismo de difusão fickiano.

\section{Agradecimentos}

À CAPES pela bolsa de mestrado concedida à Patrícia Yassue Cordeiro.

\section{Referências}

1. Fajardo, A. R., Lopes, L. C., Caleare, A. O., Britta, E. A., Nakamura, C. V., Rubira, A. F., \& Muniz, E. C. (2013). Silver sulfadiazine loaded chitosan/chondroitin sulfate films for a potential wound dressing application. Materials Science and Engineering C, 33(2), 588-595. http://dx.doi.org/10.1016/j. msec.2012.09.025. PMid:25427460.

2. Ravi, K. (2000). A review of chitin and chitosan applications. Reactive \& Functional Polymers, 46(1), 1-27. http://dx.doi. org/10.1016/S1381-5148(00)00038-9.

3. Goy, R. C., Britto, D., \& Assis, O. B. G. (2009). A review of the antimicrobial activity of chitosan. Polimeros: Ciência e Tecnologia, 19(3), 241-247.

4. Kurita, K. (1998). Chemistry and application of chitin and chitosan. Polymer Application and Stability, 59(1-3), 117-120. http://dx.doi.org/10.1016/S0141-3910(97)00160-2.

5. Giannetto, P. G., Rendón, A. M., \& Fuentes, G. R. (2000). Zeolitas: características, propriedades y aplicaciones industriales (2. ed). Venezuela: Edditorial Innovación Tecnológica, Facultad de Ingeniería, UCV.

6. Kwakye-Awuah, B., Williams, C., Kenward, M. A., \& Radecka, I. (2008). Antimicrobial action and efficiency of silver-loaded zeolite X. Journal of Applied Microbiology, 104(5), 15161524. http://dx.doi.org/10.1111/j.1365-2672.2007.03673.x. PMid:18179543.

7. Ferreira, L., Fonseca, A. M., Botelho, G., Almeida-Aguiar, C., \& Neves, I. C. (2012). Antimicrobial activity of faujasite zeolites doped with silver. Microporous and Mesoporous Materials, 160, 126-132. http://dx.doi.org/10.1016/j.micromeso.2012.05.006.

8. Lalueza, P., Monzón, M., Arruebo, M., \& Santamaria, J. (2011). Antibacterial action of Ag-containing MFI zeolite at low Ag loadings. Chemical Communications, 47(2), 680-682. http:// dx.doi.org/10.1039/C0CC03905E. PMid:21103583.

9. Boschetto, D. L., Lerin, L., Cansian, R., Pergher, S. B. C., \& Di Luccio, M. (2012). Preparation and antimicrobial activity of polyethylene composite films with silver exchanged zeolite-Y. Chemical Engineering Journal, 204-206, 210-216. http://dx.doi. org/10.1016/j.cej.2012.07.111. 
10. Pehlivan, H., Balköse, D., Ülkü, S., \& Tihminlioğlu, F. (2005) Characterization of pure and silver exchanged natural zeolite filled polypropylene composite films. Composites Science and Technology, 65(13), 2049-2058. http://dx.doi.org/10.1016/j. compscitech.2005.04.011.

11. Silva, C. F., \& Fernandes-Machado, N. R. C. (1994). Estudo da troca iônica em zeólita Y. Revista Unimar, 16(3), 463-479.

12. American Society for Testing and Materials-ASTM. (1995). ASTM D-882: tensile properties of thin plastic sheeting. West Conshohocken: ASTM. Annual Book of ASTM Standards.

13. American Society for Testing and Materials - ASTM. (1995). ASTM E96-95: standard test methods of water vapor transmission of materials. West Conshohocken: ASTM.

14. Guisnet, M., \& Ribeiro, F. R. (2004). Zeólitos: um nanomundo ao serviço da catálise. Lisboa: Fundação Calouste Gulbekian.

15. Weitkamp, J., \& Puppe, L. (1999). Catalysis and zeolites: fundamentals and applications. New York: Springer-Verlag Berlin Heidelberg. http://dx.doi.org/10.1007/978-3-662-03764-5.

16. Guerra, R., Lima, H., Viniegra, M., Guzmán, A., \& Lara, V. (2012). Growth of Escherichia coli and Salmonella typhiinhibited by fractal silver nanoparticles supported on zeolites. Microporous and Mesoporous Materials, 147(1), 267-273. http://dx.doi org/10.1016/j.micromeso.2011.06.031.

17. Lin, L., Zhang, Y., Zhang, H., \& Lu, F. (2011). Adsorption and solvent desorption behavior of ion-exchanged modified Y zeolites for sulfur removal and for fuel cell applications. Journal of Colloid and Interface Science, 360(2), 753-759. http://dx.doi.org/10.1016/j.jcis.2011.04.075. PMid:21565351.

18. Fonseca, A. M., \& Neves, I. C. (2013). Study of silver species stabilized in different microporous zeolites. Microporous and Mesoporous Materials, 181, 83-87. http://dx.doi.org/10.1016/j. micromeso.2013.07.018

19. Saint-Cricq, P., Kamimura, Y., Itabashi, K., Sugawara-Narutaki, A., Shimojima, A., \& Okubo, T. (2012). Antibacterial activity of silver-loaded "green zeolites". European Journal of Inorganic Chemistry, 2012(21), 3398-3402. http://dx.doi.org/10.1002/ ejic. 201200476.

20. Kulprathipanja, S. (2010). Zeolites in industrial separation and catalysis. Weinheim: Wiley-VCH Verlag $\mathrm{GmbH} \& \mathrm{Co}$ KGaA.

21. Garza, R. M., Olguín, M. T., Sosa, I. G., Alcántara, D., \& Fuentes, G. R. (2000). Silver supported on natural Mexican zeolite as an antibacterial material. Microporous and Mesoporous Materials, 39(3), 431-444. http://dx.doi.org/10.1016/S13871811(00)00217-1.

22. Lalueza, P., Carmona, D., Monzón, M., Arruebo, M., \& Santamaría, J. (2012). Strong bactericidal synergy between peracetic acid and silver-exchanged zeolites. Microporous and Mesoporous Materials, 156, 171-175. http://dx.doi. org/10.1016/j.micromeso.2012.02.035.

23. Shi, H., Liu, F., \& Xue, L. (2013). Fabrication and characterization of antibacterial PVDF hollowfibre membrane by doping Agloaded zeolites. Journal of Membrane Science, 437, 205-215. http://dx.doi.org/10.1016/j.memsci.2013.03.009.

24. Salavati-Niasari, M. (2009). Synthesis and characterization of 18- and 20-membered hexaaza macrocyclescontaining pyridine manganese(II) complex nanoparticles dispersed within nanoreactors of zeolite-Y. Polyhedron, 28(12), 23212328. http://dx.doi.org/10.1016/j.poly.2009.04.018.

25. American Society for Testing and Materials - ASTM. (1991). D-3906-80: standard test method for relative zeolite diffraction intensity. West Conshohocken: ASTM.

26. Wani, M. Y., Hasan, N., \& Malik, M. A. (2010). Chitosan and aloe vera: two gifts of nature. Journal of Dispersion Science and Technology, 31(6), 799-811. http://dx.doi org/10.1080/01932690903333606.
27. Wang, G., Ao, Q., Gong, K., Wang, A., Zheng, L., Gong, Y., \& Zhang, X. (2010). The effect of topology of chitosan biomaterials on the differentiation and proliferation of neural stem cells. Acta Biomaterialia, 6(9), 3630-3639. http://dx.doi. org/10.1016/j.actbio.2010.03.039. PMid:20371303.

28. Estevam, L. S., Debone, H. S., Yoshida, C. M. P., \& Silva, C. F (2012). Adsorption of bovine serum and bovine haemoglobin onto chitosan film. Adsorption Science and Technology, 30(89), 785-792.

29. Wang, J., Zheng, X., Wu, H., Zheng, B., Jiang, Z., Hao, X. \& Wang, B. (2008). Effect of zeolites on chitosan/zeolite hybrid membranes for direct methanol fuel cell. Journal of Power Sources, 178(1), 9-19. http://dx.doi.org/10.1016/j. jpowsour.2007.12.063.

30. Wang, Y., Yang, D., Zheng, X., Jiang, Z., \& Li, J. (2008). Zeolite beta-filled chitosan membrane with low methanol permeability for direct methanol fuel cell. Journal of Power Sources, 183(2), 454-463. http://dx.doi.org/10.1016/j.jpowsour.2008.06.003.

31. Araújo, P. M. A. G., Santos, P. T. A., Costa, A. C. F. M., \& Araújo, E. M. (2012). Obtenção de filmes de quitosana para aplicação em engenharia de tecido. In Anais do $7^{\circ}$ Congresso Latino Americano de Órgãos Artificiais e Biomateriais COLAOB. Natal.

32. Assis, O. B. G., \& Silva, V. L. (2003). Caracterização estrutural e da capacidade de absorção de água em filmes finos de quitosana processados em diversas concentrações. Polímeros: Ciência e Tecnologia, 13(4), 223-228.

33. Cui, Z., Xing, W., Liu, C., Liao, J., \& Zhang, H. (2009). Chitosan/heteropolyacid composite membranes for direct methanol fuel cell. Journal of Power Sources, 188(1), 24-29. http://dx.doi.org/10.1016/j.jpowsour.2008.11.108.

34. Santos, G. H., Debone, H., Yoshida, C. M. P., Silva, C. F., \& Felisbino, R. F. (2012). Avaliação das propriedades mecânicas e de barreira de filmes de quitosana contendo zeólitas para aplicação em curativos. In Anais do XIX Congresso Brasileiro de Engenharia Química. Búzios.

35. Fiori, A. P. S. M., Gabiraba, V. P., Praxedes, A. P. P., Nunes, M. R. S., Balliano, T. L., Silva, R. C., Tonholo, J., \& Ribeiro, A. S. (2014). Preparação e caracterização de nanocompósitos poliméricos baseados em quitosana e argilo minerais. Polimeros: Ciência e Tecnologia, 24(5), 628-635. http://dx.doi. org/10.1590/0104-1428.1572.

36. Ruiz-Cardona, L., Sanzgiri, Y. D., Benedetti, L. M., Stella, V. J., \& Topp, E. M. (1996). Applicationof benzyl hyaluronate membranes as potential wound dressings: evaluation of water vapour and gas permeabilities. Biomaterials, 17(16), 16391643. http://dx.doi.org/10.1016/0142-9612(95)00324-X. PMid:8842370.

37. Yannas, I. V., \& Burke, J. F. (1980). Design of an artificial skin Basic design principles. Journal of Biomedical Materials Research, 14(1), 65-81. http://dx.doi.org/10.1002/jbm.820140108. PMid:6987234.

38. Dallan, P. R. M. (2005). Síntese e caracterização de membranas de quitosana para aplicação na regeneração de pele (Tese de doutorado). Faculdade de Engenharia Química, Universidade Estadual de Campinas, Campinas.

39. Wu, Y. B., Yu, S. H., Mi, F. L., Wu, C. W., Shyu, S. S., Peng, C. K., \& Chao, A. C. (2004). Preparation and characterization on mechanical and antibacterial properties of chitosana/cellulose blends. Carbohydrate Polymers, 57(4), 435-440. http://dx.doi. org/10.1016/j.carbpol.2004.05.013.

40. Mi, F. L., Shyu, S. S., Wu, Y. B., Lee, S. T., Shyong, J. Y., \& Huang, R. N. (2001). Fabrication and characterization of sponge-like asymmetric chitosan membrane as a wound dressing. Biomaterials, 22(2), 165-173. http://dx.doi.org/10.1016/ S0142-9612(00)00167-8. PMid:11101160. 
41. Kim, I. Y., Yoo, M. K., Seo, J. H., Park, S. S., Na, H. S., Lee, H. C., Kim, S. K., \& Cho, C. S. (2007). Evaluation of semiinterpenetrating polymer networks composed of chitosan and poloxamer for wound dressing application. International Journal of Pharmaceutics, 341(1-2), 35-43. http://dx.doi.org/10.1016/j. ijpharm.2007.03.042. PMid:17482781.

42. Wang, L., Khor, E., Wee, A., \& Lim, L. Y. (2002). Chitosanalginate PEC membrane as wound dressing: assessment of incisional wound healing. Journal of Biomedical Materials Research, 63(5), 610-618. http://dx.doi.org/10.1002/jbm.10382. PMid:12209908.

43. Remuñán-López, C., \& Bodmeier, R. (1997). Mechanical, water uptake and permeability properties of crosslinked chitosan glutamate and alginate films. Journal of Controlled Release, 44(2-3), 215-225. http://dx.doi.org/10.1016/S01683659(96)01525-8.

44. Wu, P., Fisher, A. C., Foo, P. P., Queen, D. E., \& Gaylor, J. D. S. (1995). In vitro assessment of water vapour transmission of synthetic wound dressings. Biomaterials, 16(3), 171-175. http:// dx.doi.org/10.1016/0142-9612(95)92114-L. PMid:7748992.

45. Walker, M., Cochrane, C. A., Bowler, P. G., Parsons, D., \& Bradshaw, P. (2006). Silver deposition and tissue staining associated with wound dressings containing silver. Ostomy/ Wound Management, 52(1), 42-44. PMid:16464990.

46. Demling, R. H., \& Desanti, L. (2001). Effects of silver on wound management. Wounds Supplies. A, 5, 4-15.

47. Matsumura, Y., Yoshikata, K., Kunisaki, S., \& Tsuchido, T. (2003). Mode of bactericidal action of silver zeolite and its comparison with that of silver nitrate. Applied and Environmental Microbiology, 69(7), 4278-4281. http://dx.doi.org/10.1128/ AEM.69.7.4278-4281.2003. PMid:12839814.

48. Higuchi, T. (1963). Mechanism of sustained-action medicationtheoretical analysis of rate of release of solid drugs dispersed in solid matrices. Journal of Pharmaceutical Sciences, 52(12), 1145-1149. http://dx.doi.org/10.1002/jps.2600521210. PMid:14088963.

49. Wagner, J. G. (1969). Interpretation of percent dissolved-time plots derived from in vitro testing of conventional tablets and capsules. Journal of Pharmaceutical Sciences, 58(10), 1253 1257. http://dx.doi.org/10.1002/jps.2600581021. PMid:5349114.

50. Korsmeyer, R. W., Gurny, R., Doelker, E., Buri, P., \& Peppas, N. A. (1983). Mechanisms of solute release from porous hydrophilic polymers. International Journal of Pharmaceutics, 15(1), 25-35. http://dx.doi.org/10.1016/0378-5173(83)90064-9.

51. Peppas, N. A., \& Sahlin, J. J. (1989). A simple equation for the description of solute release. III. Coupling of diffusion and relaxation. International Journal of Pharmaceutics, 57(2), 169-172. http://dx.doi.org/10.1016/0378-5173(89)90306-2.

52. Lopes, C. M., Lobo, J. M., \& Costa, P. (2005). Formas farmacêuticas de liberação modificada: polímeros hidrifílicos. Revista Brasileira de Ciências Farmacêuticas, 41(2), 143-154. http://dx.doi.org/10.1590/S1516-93322005000200003.
53. Costa, P., \& Lobo, J. M. S. (2001). Modeling and comparison of dissolution profiles. European Journal of Pharmaceutical Sciences, 13(2), 123-133. http://dx.doi.org/10.1016/S09280987(01)00095-1. PMid:11297896.

54. Balcerzak, J., \& Mucha, M. (2010). Analysis of model drug release kinetics from complex matrices of polylactide-chitosan. Progress on Chemistry and Application of Chitin and its Derivatives, 15, 117-125.

55. Peppas, N. A. (1985). Analysis of fickian and non-fickian drug release from polymers. Pharmaceutica Acta Helvetiae, 60(4), 110-111. PMid:4011621.

56. Agnihotri, S. A., \& Aminabhavi, T. M. (2004). Controlled release of clozapine through chitosan microparticles prepared by a novel method. Journal of Controlled Release, 96(2), 245-259. http://dx.doi.org/10.1016/j.jconrel.2004.01.025. PMid:15081216.

57. Ravindra, S., Mohan, Y. M., Reddy, N. N., \& Raju, K. M. (2010). Fabrication of antibacterial cotton fibres loaded with silver nanoparticles via "Green Approach". Colloids and Surfaces A: Physicochemical and Engineering Aspects, 367(1-3), 31-40. http://dx.doi.org/10.1016/j.colsurfa.2010.06.013.

58. Huang, H., Yuan, Q., \& Yang, X. (2004). Preparation and characterization of metal-chitosan nanocomposites. Colloids and Surfaces B: Biointerfaces, 39(1-2), 31-37. http://dx.doi. org/10.1016/j.colsurfb.2004.08.014. PMid:15542337.

59. Hebeish, A., El-Shafei, A., Sharaf, S., \& Zaghloul, S. (2011). Novel precursors for green synthesis and application of silver nanoparticles in the realm of cotton finishing. Carbohydrate Polymers, 84(1), 605-613. http://dx.doi.org/10.1016/j. carbpol.2010.12.032.

60. Moharram, M. A., Khalil, S. K. H., Sherif, H. H. A., \& Khalil, W. A. (2014). Spectroscopic study of the experimental parameters controlling the structural properties of chitosanAg nanoparticles composite. Spectrochimica Acta. Part A: Molecular and Biomolecular Spectroscopy, 126, 1-6. http:// dx.doi.org/10.1016/j.saa.2014.01.099. PMid:24568845.

61. Lee, H. J., \& Jeong, S. H. (2005). Bacteriostasis and skin innoxiousness of nanosize silver colloids. Textile Research Journal, 75(7), 551-556. http://dx.doi.org/10.1177/0040517505053952.

62. Hossain, F., Perales-Perez, O. J., Hwang, S., \& Román, F. (2014). Antimicrobial nanomaterials as water disinfectant : applications, limitations and future perspectives. The Science of the Total Environment, 466-467, 1047-1059. http://dx.doi. org/10.1016/j.scitotenv.2013.08.009. PMid:23994736.

Enviado: Jan. 12, 2015

Revisado: Abr. 08, 2015 Aceito: Jun. 01, 2015 